American Journal of Applied Sciences 8 (9): 848-853, 2011

ISSN 1546-9239

(C) 2011 Science Publications

\title{
Evaluation of Prophylactic and Therapeutic Effects of Silymarin on Diazepam-Induced Hepatotoxicity in Cats
}

\author{
${ }^{1}$ Bahman Mosallanejad, ${ }^{1}$ Reza Avizeh and ${ }^{2}$ Hossien Najafzadeh \\ ${ }^{1}$ Department of Clinical Sciences, \\ ${ }^{2}$ Department of Pharmacology and Toxicology, \\ Faculty of Veterinary Medicine, Shahid Chamran University, Ahvaz, Iran
}

\begin{abstract}
Problem statement: Diazepam is commonly administered for seizure control and appetite stimulant in cats. Cats may develop acute fatal hepatic necrosis after receiving oral diazepam for several days. The aim of this study was to detect the protective action of silymarin on diazepam-induced hepatotoxicity in cats. Approach: About 25 healthy cats were randomly allotted to five equal groups. Animals in group A were given diazepam (repeated dose $2.5 \mathrm{mg} \mathrm{kg}^{-1}$, p.o. q $12 \mathrm{~h}$ for 4 days); group B consisted of cats that received silymarin $\left(30 \mathrm{mg} \mathrm{kg}^{-1}\right.$, p.o. $\mathrm{q} 12 \mathrm{~h}$ for 4 days) concurrent with diazepam administration; group $\mathrm{C}$ were received silymarin like group $\mathrm{B}$, but $24 \mathrm{~h}$ after diazepam administration; group $\mathrm{D}$ were received silymarin like groups $\mathrm{C}$, but $48 \mathrm{~h}$ after diazepam administration; group $\mathrm{E}$ were received silymarin like group $\mathrm{D}$, but $72 \mathrm{~h}$ after diazepam administration. The serum concentrations of Alanine Amino Transferase (ALT), Aspartate Aminotransferase (AST), Alkaline Phosphatase (ALP), Lactate Dehydrogenase (LDH) and total and direct bilirubin were measured before diazepam administration and 24, 48, 72 and $96 \mathrm{~h}$ later as indices of liver injury. Results: Repeated oral administration of diazepam significantly elevated serum concentrations of ALT, AST, ALP, LDH and total and direct bilirubin in cats of group A, after $48 \mathrm{~h}$. In both the groups (B and C) receiving silymarin, levels of serum enzyme activities and total and direct bilirubin remained within the normal values, but the group $\mathrm{D}$ and $\mathrm{E}$ which received silymarin $48 \mathrm{~h}$ and $72 \mathrm{~h}$ later, levels of serum enzyme activities and total and direct bilirubin were increased with comparison to before diazepam administration. Conclusion: It was concluded that silymarin can protect liver tissue against oxidative stress in cats with diazepam intoxication particular in the first $24 \mathrm{~h}$ after exposure.
\end{abstract}

Key words: Silymarin, diazepam, hepatotoxicity, Alanine Amino Transferase (ALT), Gamma Glutamyl Transferase (GGT)

\section{INTRODUCTION}

Diazepam is reported to be effective as an acute and chronic anticonvulsant in cats. It has been used to treat problems such as inappropriate elimination associated with anxiety, urine marking or spraying, fear aggression and over grooming, as well as to stimulate appetite (Maddison et al., 2002). It is the most commonly used anticonvulsant followed by phenobarbitone and pentobarbital. Generally, overdoses of over the counter drugs happen either accidentally or may be due to excessive administration by a well-meaning owner. Hepatic necrosis is the most serious adverse event reported in cats, so some neurologists do not recommend the use of diazepam as a maintenance anticonvulsant in cats. Concurrent administration with other drugs that compete with the cytochrome P450 enzyme system may decrease the rate of metabolism of diazepam. This adverse effect should be carefully considered before administering diazepam to cats, especially on a long-term or recurrent basis. The cat has been used extensively as an experimental model for studying the pharmacology of drugs. If a cat taking diazepam becomes excessively depressed, vomits, stops eating or becomes jaundiced, its administration should be stopped immediately. Acute hepatic injury may be caused by a direct toxic effect of the drug or its metabolites on the hepatocyte, producing a predictable dose-dependent effect, or by idiosyncratic drug reactions, which occur unpredictably in a small number of cats exposed to a particular drug such as diazepam (Lappin, 2001). Harkin et al. (2000) suggested that stanozolol was hepatotoxic in cats.

Corresponding Author: B. Mosallanejad, Department of Clinical Sciences, Faculty of Veterinary Medicine, Shahid Chamran University, Ahvaz, Iran 
The mechanism of action of the hepatotoxicity is unknown but it has been postulated to be due to an immunologic response to reactive metabolites or to a difference in diazepam metabolism. Approximately $50 \%$ of an administered dose of diazepam is biotransformed to nordiazepam in the cat (Cotler et al., 1984). The true incidence of drug-induced hepatic disease is unknown. Clinical signs and laboratory test results are nonspecific and do not differentiate druginduced from other causes of hepatic diseases (Lappin, 2001). Laboratory abnormalities reflect hepatic injury. Elevation in ALT and AST activities are the most consistent findings. Serum ALP and Gamma Glutamyl Transferase (GGT) activities also may be increased. Bilirubinuria and hyperbilirubinemia occur more commonly in cats than in dogs (Lappin, 2001). Silymarin, an antioxidant flavonoid complex derived from the herb milk thistle (Silybum marianum), has long been used in the treatment of liver diseases (Saller et al., 2001; 2008; Wellington and Jarvis, 2001). Silymarin was chosen for this investigation because of antioxidant properties (Mahabady and Varzi, 2009). This property seems to be due to its ability to scavenge free radicals and to chelate metal ions (Das and Vasudevan, 2006). The present study was conducted to evaluate the hepatoprotective action of silymarin as the standard drug for evaluation of prophylactic and therapeutic effects on diazepam-induced hepatotoxicity in cats.

\section{MATERIALS AND METHODS}

Animals: Twenty five adult domestic short-haired cats of both sexes weighing between 2.45 and $4.35 \mathrm{~kg}$ were used. All cats appeared healthy, as determined by clinical examination, normal hematogram and clinical biochemical profiles. The cats were vaccinated with Tri-cat and rabies vaccine. Antiparasitic drugs (piperazine $100 \mathrm{mg} \mathrm{kg}^{-1}$ and praziquantel $5 \mathrm{mg} \mathrm{kg}^{-1}$ ) were administered to all cats as well as. They were fed a home-made diet containing chicken and fish. Water was provided ad libitum. This study was performed under control of Iranian Society for the Prevention of Cruelty to Animals.

Experimental protocol: The cats were allocated to five groups consisting of five cats each:

- Group A: Diazepam (Jalinous Pharmaceutical Co.,Tehran, Iran) was administered orally at a repeated dose $2.5 \mathrm{mg} \mathrm{k} \mathrm{g}^{-1}$, p.o. q $12 \mathrm{~h}$ for 4 days
- Group B: Silymarin (Sigma-Aldrich Co., St Louis, MO, USA) was administered orally at a repeated dose of $30 \mathrm{mg} \mathrm{kg}^{-1}$, in gelatin capsules, concurrent with diazepam administration

- Group C: Silymarin was administered orally at a repeated dose of $30 \mathrm{mg} \mathrm{kg}^{-1}, 24$ after diazepam administration.

- Group D: Silymarin was administered orally at a repeated dose of $30 \mathrm{mg} \mathrm{kg}^{-1}, 48$ after diazepam administration.

- Group E: Silymarin was administered orally at a repeated dose of $30 \mathrm{mg} \mathrm{kg}^{-1}, 72$ after diazepam administration.

Blood sampling and blood chemistry: Blood samples were collected from the jugular or femoral veins. Serum concentrations of ALT, AST, ALP, LDH and total and direct bilirubin were measured in an automated chemical analyzer (BT 3000 Plus, Biotechnica, Milan, Italy) using diagnostic kits (Pars Azmoon Co., Tehran, Iran) before diazepam administration and 24, 48, 72 and $96 \mathrm{~h}$ thereafter. Electrolytes such as K, Na, CL, Ca and $\mathrm{P}$ were measured in the present survey.

Data analysis: The arithmetic mean of ALT, AST, ALP, LDH, total and direct bilirubin and other parameters were compared between groups using one sample T-test, repeated measures analysis of variance and Fisher Least Significant Difference test (SPSS, version 16, SPSS Inc., Chicago, IL, USA). Differences were considered significant when $\mathrm{p}<0.05$.

\section{RESULTS}

There were differences in the enzyme activities among the different treatment groups. Repeated oral administration of diazepam significantly elevated serum concentrations of ALT, AST, ALP, LDH and total and direct bilirubin of group A. Clinical findings included depression, anorexia, ptyalism and weakness and less commonly jaundice. In both the groups (B and C) receiving silymarin, levels of serumenzyme activities and total and direct bilirubin remained within the normal values. Concurrent or therapeutic application of silymarin in the first $24 \mathrm{~h}$ improved clinical status of cats and abolished clinical signs. The groups D and E which received silymarin $48 \mathrm{~h}$ later, levels of serumenzyme activities and total and direct bilirubin levels were higher than before diazepam administration. Two and three cats from groups D and E developed signs of intoxication. Electrolyte imbalances and acidbase disturbances were not seen in the present study. 


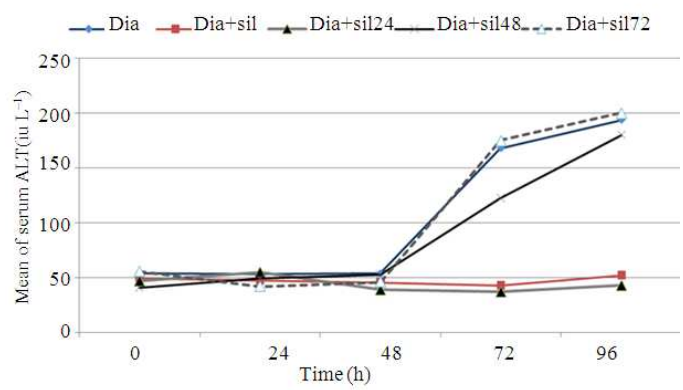

Fig. 1: The mean of serum ALT concentration of cats (A) Diazepam treated; (B) Concomitant application of diazepam and silymarin; (C) Silymarin application $24 \mathrm{~h}$ after diazepam administration (D) Silymarin application $48 \mathrm{~h}$ after diazepam administration (E) Silymarin application $72 \mathrm{~h}$ after diazepam administration

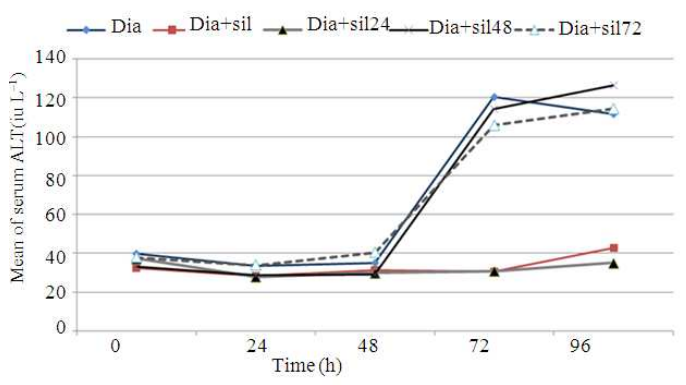

Fig. 2: The mean of serum AST concentration of cats (A) Diazepam treated; (B) Concomitant application of diazepam and silymarin; (C) Silymarin application $24 \mathrm{~h}$ after diazepam administration (D) Silymarin application $48 \mathrm{~h}$ after diazepam administration (E) Silymarin application $72 \mathrm{~h}$ after diazepam administration

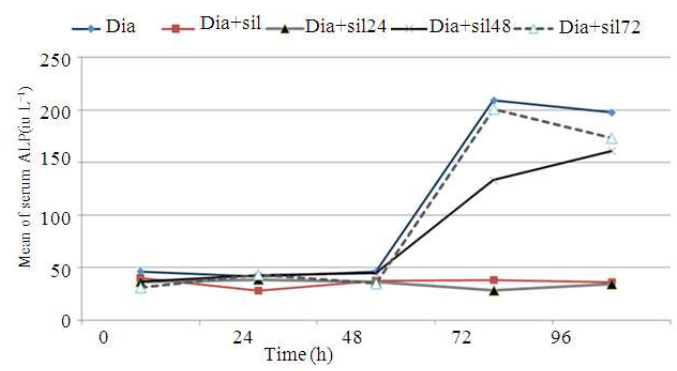

Fig. 3: The mean of serum ALP concentration of cats (A) Diazepam treated; (B) Concomitant application of diazepam and silymarin; (C) Silymarin application $24 \mathrm{~h}$ after diazepam administration (D) Silymarin application $48 \mathrm{~h}$ after diazepam administration (E) Silymarin application $72 \mathrm{~h}$ after diazepam administration

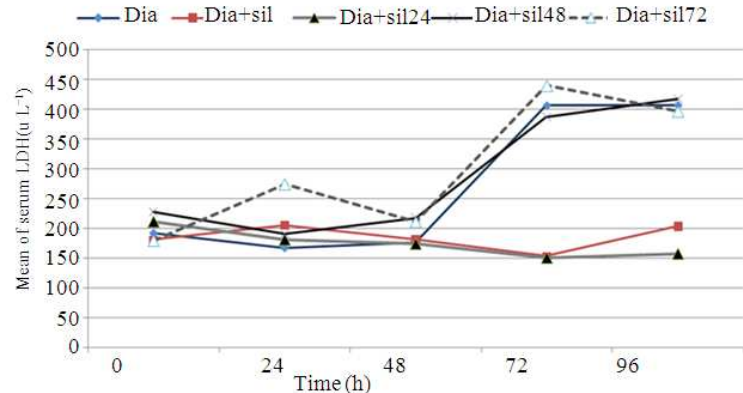

Fig. 4: The mean of serum LDH concentration of cats (A) Diazepam treated; (B) Concomitant application of diazepam and silymarin; (C) Silymarin application $24 \mathrm{~h}$ after diazepam administration (D) Silymarin application $48 \mathrm{~h}$ after diazepam administration (E) Silymarin application $72 \mathrm{~h}$ after diazepam administration

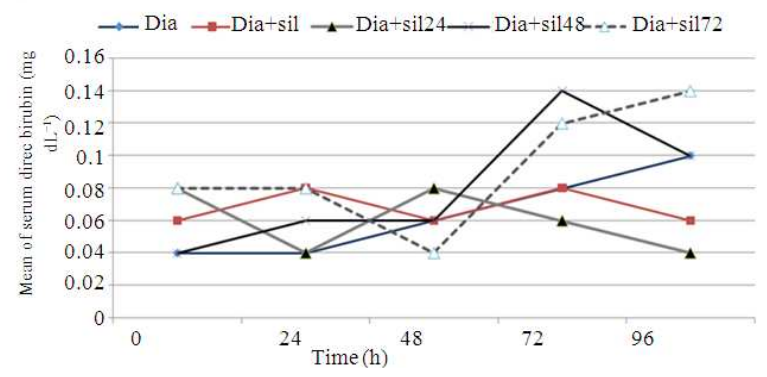

Fig. 5: The mean of serum direct bilirubin concentration of cats (A) Diazepam treated; (B) Concomitant application of diazepam and silymarin; (C) Silymarin application $24 \mathrm{~h}$ after diazepam administration (D) Silymarin application $48 \mathrm{~h}$ after diazepam administration (E) Silymarin application $72 \mathrm{~h}$ after diazepam administration

None of the cats in all groups died during the experiment. The course of the enzymatic activities and total and direct bilirubin is presented in Fig. 1-6.

Enzyme concentrations: In group A cats, after diazepam administration, ALT concentration increased after $72 \mathrm{~h}$. The mean serum ALT concentration increased from 53.8 IU/L before diazepam administration to 168 and $193.8 \mathrm{IU} / \mathrm{L}, 72$ and $96 \mathrm{~h}$ after administration respectively. Concurrent or therapeutic $(24 \mathrm{~h}$ later) application of silymarin significantly prevented an increase in serum ALT concentration in groups B and C $(\mathrm{p}<0.05)$ (Fig. 1). The mean serum ALT concentration was $180 \mathrm{IU} / \mathrm{L}$ in cats of group D 96 h later. The mean serum ALT concentration increased to $200.2 \mathrm{IU} / \mathrm{L}$, in cats of group $\mathrm{E}$ also. 


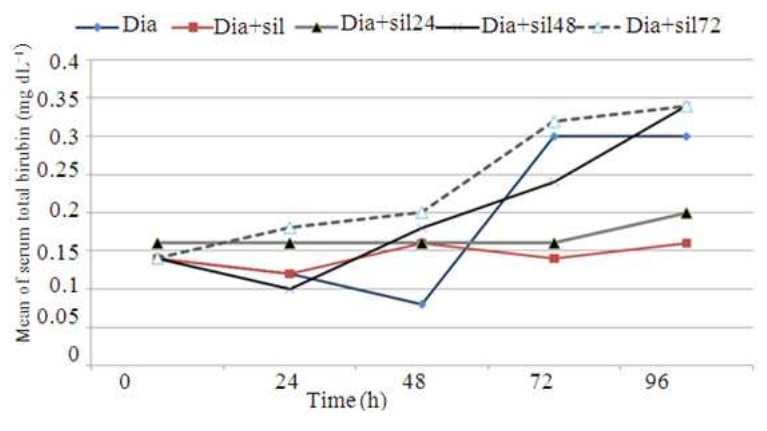

Fig. 6: The mean of serum total bilirubin concentration of cats (A) Diazepam treated; (B) Concomitant application of diazepam and silymarin; (C) Silymarin application $24 \mathrm{~h}$ after diazepam administration (D) Silymarin application $48 \mathrm{~h}$ after diazepam administration (E) Silymarin application $72 \mathrm{~h}$ after diazepam administration

Diazepam significantly increased the AST concentration in group A cats from $39.8 \mathrm{IU} / \mathrm{L}$ before to 111.6 IU/L $96 \mathrm{~h}$ after diazepam administration. This effect was prevented by silymarin in groups B and C (Fig. 2). The mean serum AST concentration was increased to $126.4 \mathrm{IU} / \mathrm{L}$ and $114.6 \mathrm{IU} / \mathrm{L} 96 \mathrm{~h}$ later in cats of group $\mathrm{D}$ and $\mathrm{E}$ respectively. The serum concentrations of ALP and LDH were also increased in the group A (197.4 IU/L and 406.8 IU/L $96 \mathrm{~h}$ later respectively) and this effect was significantly reduced by silymarin in groups B (35.8 IU/L and 203.6 IU/L 96 $\mathrm{h}$ later respectively) and C (34.2 IU/L and $157.2 \mathrm{IU} / \mathrm{L}$ $96 \mathrm{~h}$ later respectively). The mean serum ALP and LDH concentrations were increased in cats of group $\mathrm{D}$ and $\mathrm{E}$ $72 \mathrm{~h}$ later (Fig. 3). Serum total and direct bilirubin concentration increased after diazepam administration in group A within $72 \mathrm{~h}$ later $(0.7$ and $0.3 \mathrm{IU} / \mathrm{L}$ respectively). Serum total and direct bilirubin concentration was normal in cats of groups B $(0.16$ and $0.06 \mathrm{IU} / \mathrm{L}$ respectively) and $\mathrm{C}(0.2$ and $0.04 \mathrm{IU} / \mathrm{L}$ respectively) $96 \mathrm{~h}$ later (Fig. 4 and 5). The concurrent or therapeutic application of silymarin had a beneficial effect and returned serum total bilirubin concentration toward normal values in cats of groups B and C.

\section{DISCUSSION}

The results of the present study show that repeated doses of $2.5 \mathrm{mg} \mathrm{kg}^{-1}$ of diazepam q $12 \mathrm{~h}$ for four days can induce acute hepatotoxicity as verified by clinical and biochemical investigations. Repeated doses of diazepam increased serum concentrations of diagnostic liver enzymes and total and direct bilirubin in group A.
On the basis of the presumption that diazepam is a hepatotoxic drug, an increase in serum enzyme activities within $48 \mathrm{~h}$ after onset, indicates a need to suspend drug administration and to provide supportive care.

In the present survey, we used silymarin for prevention of hepatotoxicity effects of diazepam in cats. Many medicinal, nutraceutical and botanic extracts such as $\mathrm{S}$-adenosylmethionine, $\mathrm{N}$-acetylcysteine, ursodeoxycholic acid, silymarin and vitamin $\mathrm{E}$ have been used as cytoprotective agents in liver disease (Webster and Cooper, 2009). Various dosages of diazepam were used in other studies for diazepam toxicity. Acute fulminant hepatic necrosis was associated with repeated oral administration of diazepam (1.25-2 mg, PO, q 24 or $12 \mathrm{~h}$ ), prescribed for behavioral modification or to facilitate urination (center et al., 1996). In their reports, five of 11 cats became lethargic, ataxic and anorectic within $96 \mathrm{~h}$ of initial treatment. All cats became jaundiced during the first 11 days of illness. Serum biochemical analysis revealed profoundly high ALT and AST activities (Center et al., 1996). Silymarin can protect liver tissue against oxidative stress in cats with different intoxications. Host factors such as age, sex, individual genetic constitution, nutrition, disease status and prior or concomitant use of other medications can affect the likelihood and severity of drug-induced hepatic disease. Reduced protein binding in very young cats may alter the hepatotoxic potential of highly protein-bound agents. The rate of metabolism of some drugs may be decreased in younger cats because of lower hepatic enzyme activities. Older cats are more likely to have preexisting disease and alterations in hepatic blood flow that affect rates of drug metabolism and ability to compensate for hepatic injury. Females may be predisposed to drug-induced hepatic disease because of higher drug-metabolizing hepatic enzyme activities and increased capacity to generate toxic metabolites. Genetic make-up is important in measuring hepatic enzyme activities and inherited enzyme defects may significantly alter drug metabolizing capacity. If dietary protein intake is inadequate, cats rapidly become deficient in important cellular proteins, including carrier proteins and enzymes that are necessary components of drug metabolic pathways. Another species variation affecting drug metabolism in cats is a relative deficiency of glucuronyl transferase, which mediates conjugation of various drugs to glucuronide for elimination (Lappin, 2001; Maddison et al., 2002). The prophylactic and treatment effects of administration of silymarin, role of serumenzyme activities in diazepam-induced hepatotoxicity and 
preventive and therapeutic effects of silymarin in this study was similar to study of Avizeh et al. (2010). In their research, a single oral administration of acetaminophen significantly elevated serum concentrations of ALT, AST, ALP, LDH, methemoglobin and total and direct bilirubin. In both the groups receiving acetaminophen plus $\mathrm{N}$ acetylcysteine or silymarin, levels of serumenzyme activities, methemoglobin and total and direct bilirubin remained within the normal values. Silymarin and vitamin $\mathrm{E}$ decreased gentamicin-induced nephrotoxicity in dogs. In another research, serum creatinine and urea concentrations were increased in the dogs under administration of gentamicin (induced nephrotoxicity) (Varzi et al., 2007). Silymarin alone or in supplement with other drugs, can influence the therapy of many diseases of liver in many species of animals. (Oliveira et al., 2001; Sumathy et al., 2001; Kalender et al., 2005; Dehghan et al., 2010).

The result of therapeutic dose of silymarin $(24 \mathrm{~h}$ after administration of diazepam) was similar to prophylactic dose (co-administration of both the drugs) in prevention of hepatotoxicity in the present study. Clinical signs consistent with drug-induced hepatic disease. The most common clinical signs were depression, anorexia, ptyalism, weakness and less commonly jaundice. We didn't see signs such as hemorrhage or petechiation and neurologic signs of hepatic encephalopathy.

Most cases of drug-induced hepatopathy are mild and present with vague signs of lethargy and anorexia with or without vomiting or jaundice. Hepatotoxicity of individual drugs varies significantly among species. Agents known to be hepatotoxic in other species can not be assumed to be hepatotoxic in cats. Likewise, agents may cause hepatic injury in cats but not in other species. Malnutrition, especially protein deficiency, adversely affects hepatic enzyme and protein carrier systems and is of great significance in cats, which depend on dietary protein intake to meet energy as well as protein requirements. Silymarin is a scavenger of radicals, such as hydroxyl, superoxide and hydrogen peroxide $\left(\mathrm{H}_{2} \mathrm{O}_{2}\right)$; increases Sorbitol Dehydrogenase; and decreases lipid peroxidation (Lappin, 2001; Oliveira et al., 2001). It protects liver cells directly by stabilizing the membrane permeability through inhibiting lipid peroxidation (Najafzadeh et al., 2010; Mira et al., 1994) and prevents liver glutathione depletion (Valenzuela and Garrido, 1994). The major activity of sylimarine is their antioxidant property, which makes them useful in the prevention of other organ-specific toxicities related to the induction of oxidative stress (Varzi et al., 2007). Owner education and follow-up is recommended to avoid hepatotoxicity when prescribing diazepam for anxiety-related behavior problems in cats.

\section{CONCLUSION}

In conclusion, the results of this study showed that silymarin has protective effect in prophylaxis and treatment of diazepam-induced hepatotoxicity in cats and might provide a useful therapy in cats at least in the first $24 \mathrm{~h}$ of intoxication.

\section{ACKNOWLEDGMENT}

The researchers wish to express their gratitude to the research council of Shahid Chamran University of Ahvaz for financial support.

\section{REFERENCES}

Avizeh, R., H. Najafzadeh, J. Razijalai and S. Shirali, 2010. Evaluation of prophylactic and therapeutic effects of silymarin and $\mathrm{N}$-acetylcysteine in acetaminophen-induced hepatotoxicity in cats. J. Vet. Pharmacol. Ther., 33: 95-99. PMID: 20444031

Cotler, S. J.H. Gustafson and W.A. Colburn, 1984. Pharmacokinetics of diazepam and nordiazepam in the cat. J. Pharm. Sci., 73: 348-351. PMID: 6425492

Das, S.K. and D.M. Vasudevan, 2006. Protective effects of silymarin, a milk thistle (Silybium marianum) derivative on ethanol-induced oxidative stress in liver. Indian J. Biochem. Biophy., 43: 306311. PMID: 17133738

Dehghan, A., A.A. Mahjoor, H. Bazyar and K. Zangili, 2010. Effects of silymarin and food restriction on hepatic and pancreatic functions in wistar rats. Asian J. Anim. Vet. Adv., 5: 136-142. DOI: 10.3923/ajava.2010.136.142

Harkin, K.R., L.A. Cowan, G.A. Andrews, R.J. Basaraba and J.R. Fischer et al., 2000. Hepatotoxicity of stanozolol in cats. J. Am. Vet. Med. Assoc., 217: 681-684. PMID: 10976299

Kalender, Y., M. Yel and S. Kalender, 2005. Doxorubicin hepatotoxicity and hepatic free radical metabolism in rats. The effects of vitamin $\mathrm{E}$ and catechin. Toxicology, 209: 39-45. PMID: 15725512

Lappin, M.R., 2001. Feline Internal Medicine Secrets. 4th Edn., Elsevier Health Sciences, Philadelphia, ISBN-10: 1560534613, pp: 479. 
Mahabady, M.K. and H.N. Varzi, 2009. A comparison study of effects of vitamin $\mathrm{E}$ and silymarin on phenytoin-induced cleft palate in rats. J. Biol. Sci., 9: 381-384.

Maddison, J.E., S.W. Page and D.B. Church, 2002. Small Animal Clinical Pharmacology. 1st Edn., Elsevier Health Sciences, London, ISBN: 0702025739, pp: 575.

Mira, L., M. Silva and C.F. Manso, 1994. Scavenging of reactive oxygen species by silibinin dihemisuccinate. Biochem. Pharmacol., 48: 753759. PMID: 8080448

Najafzadeh, H., M.R. Jalali, H. Morovvati and F. Taravati, 2010. Comparison of the prophylactic effect of silymarin and deferoxamine on iron overload-induced hepatotoxicity in rat. J. Med. Toxicol., 6: 22-26. PMID: 20182837

Oliveira, C.P., F.P. Lopasso, F.R. Laurindo, R.M. Leitao and A.A. Laudanna, 2001. Protection against liver ischemia-reperfusion injury in rats by silymarin or verapamil. Transplant. Proc., 33: 3010-3014. PMID: 11543828

Saller, R., R. Brignoli, J. Melzer and R. Meier, 2008. An updated systematic review with meta-analysis for the clinical evidence of silymarin. Forsch Komplementmed, 15: 9-20. PMID: 18334810
Saller, R., R. Meier and R. Brignoli, 2001. The use of silymarin in the treatment of liver diseases. Drugs, 61: 2035-2063. PMID: 11735632

Sumathy, T., S. Subramanian, S. Govindasamy, K. Balakrishna and G. Veluchamy, 2001. Protective role of bacopa monniera on morphine induced hepatotoxicity in rats. Phytother. Res., 15: 643-645. PMID: 11746853

Valenzuela, A. and A. Garrido, 1994. Biochemical bases of the pharmacological action of the flavonoid silymarin and of its structural isomer silibinin. Biol. Res., 27: 105-112. PMID: 8640239

Varzi, H.N., S. Esmailzadeh, H. Morovvati, R. Avizeh and A. Shahriari et al., 2007. Effect of silymarin and vitamin $\mathrm{E}$ on gentamicin-induced nephrotoxicity in dogs. J. Vet. Pharmacol. Ther., 30: 477-481. PMID: 17803742

Webster, C.R. and J. Cooper, 2009. Therapeutic use of cytoprotective agents in canine and feline hepatobiliary disease. Vet. Clin. North Am. Small Anim. Pract., 39: 631-52. PMID: 19524797

Wellington, K. and B. Jarvis, 2001. Silymarin: A review of its clinical properties in the management of hepatic disorders. BioDrugs, 15: 465-489. PMID: 11520257 